\title{
Appropriateness and Factors Associated with Antibiotics Prescription to Outpatients with Respiratory Tract Infection in Tema Polyclinic, Ghana.
}

Joel Jeffrey Idun-Acquah

Tema Polyclinic

Michael Mireku Opoku

University of Ghana School of Public Health

Ernest Kenu

University of Ghana School of Public Health

Harriet Affran Bonful ( $\square$ habonful@ug.edu.gh )

University of Ghana School of Public Health https://orcid.org/0000-0003-0069-3241

\section{Research}

Keywords: Appropriateness, antibiotics, factors, prescriptions, respiratory tract infections, Tema Polyclinic, Ghana

Posted Date: July 14th, 2020

DOI: https://doi.org/10.21203/rs.3.rs-41132/v1

License: (c) (i) This work is licensed under a Creative Commons Attribution 4.0 International License. Read Full License 


\section{Abstract}

Background: Appropriate prescription of antibiotics, consistent with nationally approved guidelines for the management of patients with respiratory tract infections (RTI) is an important step to reduce antibiotics resistance. This study assessed the appropriateness and factors associated with antibiotic prescription among RTI outpatients at the Tema Polyclinic in Ghana.

Methods: Records of 600 outpatients diagnosed with at least one RTI condition between $1^{\text {st }}$ July and $31^{\text {st }}$ December, 2018 were manually retrieved and assessed in an analytic cross-sectional study. The outcomes were the proportion of RTI cases appropriately managed with antibiotics using Kunin's modified criteria and antibiotic prescription. Independent variables included sociodemographic factors, clinical factors and prescriber's professional category. Univariable logistic regression was used to estimate crude odds ratios for factors associated with antibiotic prescription. A threshold of $p<0.20$ was used to include factors into a multivariable logistic regression model. Adjusted odds ratios were estimated using backward stepwise logistic regression. Statistical significance was set at $p<0.05$.

Results: The proportion of RTI cases which were prescribed with at least one antibiotic was $59.7 \%$ (358/600). Majority of RTI cases (68.2\%) had non-specific diagnoses. Of the $32.8 \%$ (121/600) with specific diagnoses, $(63.3 \%, 95 \% \mathrm{Cl}: 56.2,69.9)$ were appropriately prescribed with antibiotics. Inadequate dosage duration accounted for most of the inappropriately prescribed antibiotics. The factors which were independently associated with reduced odds of antibiotic prescription were presenting with catarrh, diagnosis of rhinitis, acute respiratory tract infection, upper respiratory tract infection, and common cold. Requesting laboratory investigations, presenting with breathlessness, headache and sputum production were associated with increased odds of antibiotic prescription in the adjusted model.

Conclusion: Majority of patients with specific diagnoses were prescribed antibiotics appropriately. However, most cases could not be evaluated for appropriateness because the diagnoses were non-specific. The frequency of antibiotic prescription was high. Antibiotic stewardship efforts should focus on imparting knowledge on specific diagnoses and corresponding treatment with emphasis on dosage regimen while deemphasizing symptomatic treatment based on sputum production.

\section{Background}

Respiratory tract infections (RTIs) are among the most common acute illnesses seen by physicians at the outpatients department (OPD) in majority of primary healthcare facilities globally $(1-5)$. The incidence of RTI is higher in children and responsible for most hospital admissions, especially among those younger than 5 years $(1,6,7)$. In 2016, RTIs (mainly lower respiratory tract infections, LRTI) accounted for $5.2 \%$ $(2,964,000)$ of total deaths from all causes globally (8). Deaths attributable to RTIs in 2016 alone for Ghana was 140.0 per 100,000 population with $1,085,100$ disability-adjusted life years (DALYs) $(8,9)$. There has been a drop in morbidity from $18.3 \%$ in 2016 to $12.5 \%$ in 2017 in the Ghanaian public sector(10) .

To rationalise the use of antibiotics in the management of RTI, the National Institute for Health and Clinical Excellence (NICE) of Great Britain has recommended that 
1. serious conditions which may require antibiotics such as bacterial pneumonia as required by available treatment guidelines need to be ruled out

2. the patient or caregiver of a child is educated and reassured, and

3. symptomatic relief is provided those who do not require antibiotics $(11,12)$.

Other strategies to improve on use of antibiotics in RTI management include avoiding, delaying or deferring the prescribing of antibiotics $(12,13)$. The treatment recommendations by the Ghana Standard Treatment Guidelines (STG) is similar to the above in managing specified RTIs. Additionally, strategies such as antibiotic stewardship and provision of guidelines, clinician and patient education have been shown to be valuable (14-16). For instance, the existence of functional drugs and therapeutic committees (DTCs) which has responsibility for antibiotic stewardship in hospitals promotes rational prescription of antibiotics and compliance to guidelines $(7,17)$.

However, use of standard protocols for treatment of RTI, especially in terms of antibiotic prescription, has not been adequate. In spite of the fact that most RTIs are viral in aetiology and thus self-limiting, several studies have identified frequent use of antibiotics in their management across the globe $(4,5,12,18,19)$. The high rate of antibiotic use in RTI management is often associated with inappropriate prescription. A study in the USA among veterans found that only $11 \%$ of antibiotics were optimally prescribed for management of RTI, with $89 \%$ being inappropriate (20). Prescription rates of above $50 \%$ have been reported in some developed countries $(11,12,21,22)$. In Africa, antibiotic prescription rates between $26 \%$ and $70 \%$ have been observed $(18,23-25)$. A study conducted among children in two facilities in Ghana reported that $30-65 \%$ of the RTI cases were inappropriately prescribed antibiotics (18). Inappropriately prescribed antibiotics can lead to antibiotic resistance $(23,26,27)$. Thus, ensuring the appropriate prescription of antibiotics in the management of RTI is a key step in combatting antimicrobial resistance (12). Reduction in inappropriate antibiotic prescription is also key in reducing needless exposure to potential side effects/adverse reactions from antibiotics, drug interactions and increased medical cost $(11,12,28)$.

Patient, physician and institutional factors are associated with antibiotic prescription. While a physician's area of specialty, and perceptions of a patient's desire for antibiotics $(31,34,35)$ can influence prescribing behaviour, some diagnoses such as bronchitis, or symptoms including coloured sputum, nasal discharge, fever, breathlessness, bronchial exudates, and requests for laboratory investigations, are associated with antibiotic prescription(29-35).

In Ghana, the Ministry of Health and Ghana Health Service have been organizing trainings and seminars for health workers on appropriate use of antibiotics and rational use of medicines. The national antimicrobial policy was also recently launched as part of broad measures to address antimicrobial resistance in Ghana (36) .

Despite all these measures, antibiotic prescription per patient encounter at the OPD of Tema polyclinic has remained above 40\% for three consecutive years (i.e. 53.3, 51.9 and 46.0\% in 2016, 2017 and 2018 respectively). These rates are above the National and WHO target of less than $30 \%$. Additionally, there has been increased claims-rejection by the national health insurance scheme (NHIS) for patients diagnosed with RTI, majority of whom were prescribed antibiotics (37). These underscore the need for a thorough 
assessment of the appropriateness of antibiotic use in the facility. Kunin's criteria modified by Deshmuk and colleagues, is a tool with standardized indicators and as such is reliable for such an assessment (28). Its use requires that treatments are standardized for purposes of benchmarking. In Ghana, the Standard Treatment Guideline (STG) serves this purpose (38). Generally, the STG recommends the identification of signs of suprainfection either by symptom or clinical investigation before antibiotic prescription. Regular audit of prescriptions at the OPD to ascertain their appropriateness is necessary to identify and address inappropriate use at the facility level. It will also contribute to the promotion of practices that will reduce the development of antibiotic resistance. Therefore, this study was designed to assess the appropriateness of antibiotic prescription to RTI outpatients and identify the factors associated with antibiotic prescription at the Tema Polyclinic in Ghana.

\section{Methods}

\section{Study location}

The study was conducted at the Tema Polyclinic in the Greater Accra region of Ghana. In 2018, the Polyclinic served as the main sub-metropolitan primary health care facility for the Tema West submetropolis with an estimated population of 138,410 . The facility has 6 medical doctors in general practice, 2 obstetrician/gynaecologists, 2 dental surgeons, 6 physician assistants and 4 nurse prescribers.

The medical laboratory is staffed with 4 biomedical scientists and equipped to undertake the tests for which data were collected in the study, except for culture and sensitivity testing, which patients had to get from elsewhere. The Pharmacy unit supplies various classes of antibiotics once a valid prescription is presented.

\section{Study design}

This was a facility-based retrospective analytic cross-sectional study. Data were extracted from folders of patients who had been diagnosed with a specific or non-specific RTI at the out-patient department (OPD) of the polyclinic from $1^{\text {st }}$ July to $31^{\text {st }}$ December, 2018. The specific RTI diagnoses included otitis media, bronchitis, common cold, pharyngitis, pneumonia, rhinitis, tonsillitis and sinusitis. Non-specific RTI were cases diagnosed as acute respiratory tract and upper respiratory tract infections.

\section{Eligibility criteria}

OPD folders with at least one specific or non-specific RTI diagnosis during the study period were considered to have met the inclusion criteria. Of these, those excluded were folders of pregnant women, and patients who had HIV or TB. In addition, patients who visited the dental unit on the same day RTI diagnosis was made or visited the OPD for review of previously diagnosed RTI. They were excluded because ideal antibiotic choices for such patients may rightly vary from STG recommendations which are for the general population.

\section{Sampling}


A sampling frame consisting of all 1,331 patient folders with specific or non-specific RTI diagnoses within the study period, grouped month by month, was generated. Systematic random sampling was used to select 600 folders. For each month, every third folder was selected and the process repeated if necessary, until the sample size for the month was reached.

\section{Data collection}

Ashaiman polyclinic, located in the Ashaiman Municipality, served as site for pretesting of the data collection tool. The tool was designed based on the STG and the Kunin's modified criteria (28). The tool was used to collect patients' biodata, presenting signs and symptoms, laboratory investigations, diagnoses, medicines prescribed, their doses, frequency of administration and duration of treatment, and professional category of the prescriber. The laboratory investigations included comprised blood film for malaria parasites or malaria rapid diagnostic test, full blood count, blood urea electrolytes, stool examination for parasitic infections (stool routine examination), simple urine examination for protein and haematuria (urine routine examination), urine pregnancy test, fasting blood sugar, Widal test, and sickling test. Presence or absence of the following symptoms and signs were recorded; abdominal pain, breathlessness, chest pain, cough, diarrhoea, fever, headache, malaise, nasal congestion, rapid breathing, rhinorrhea, sore throat, sneezing, wheezing, catarrh, and sputum.

Antibiotic prescription, the primary outcome, was defined as a primary visit having at least one (1) antibiotic prescribed. A prescribed medicine was considered an antibiotic if it is classified under the WHO Anatomical Therapeutic Chemical classification J01 (Antibacterials for systemic use) or P01AB (nitroimidazole derivatives) (39). Antibiotics for topical use were not included. The independent variables were grouped as sociodemographic factors, symptoms, diagnoses, laboratory investigations and prescriber's professional category.

Two pharmacists including a specialist clinical pharmacist assessed the appropriateness of antibiotics prescribed using the STG recommendations and the Kunin's modified criteria (28) as benchmark.

1. Agree with the use of antibiotic therapy given as in the prescription. The treatment is appropriate in terms of choice of antibiotic prescription or no prescription of antibiotic, dose, dosage regimen, and duration of therapy.

2. Agree with the use of antibiotic therapy because a potentially fatal infection of bacterial origin which will require antibiotic cannot be ruled out. Priority is given to saving life compared to antibiotic misuse.

3. Agree with the use of the antibiotic therapy but a different (usually less expensive and toxic) combination of therapy is preferred.

4. Agree with the use of antibiotic therapy but a modified dose, dosage regimen, and duration would be recommended.

5. Disagree with the use of antibiotic therapy; administration is unjustified or unnecessary use of drugs.

Category I and II were considered as "Appropriate" antibiotic therapy while category III, IV and V were considered as "Inappropriate" antibiotic therapy. Appropriateness of antibiotic prescription was defined as 
the proportion of all antibiotics with specific diagnoses (Categories I, II, III, IV and V) categorized as appropriate (categories I and II).

Information on drug use training was obtained from in-service training reports using a data extraction tool. A checklist was used to assess the availability of STGs in the consulting rooms and medicines in the pharmacy stores.

\section{Data management and analysis}

Data were double entered into Epi Info version 7.2.2.6 and checked for completeness and discrepancies.

A frequency table was used to present biodata of patients and professional category of prescribers. Frequencies were used to describe the types of antibiotics prescribed. Appropriateness of antibiotic prescriptions were estimated using proportions with 95\% confidence Interval $(\mathrm{Cl})$. Chi-square test (or fisher's exact test, where appropriate) was used to examine the association between antibiotic prescription and the independent variables. Crude odds ratio of the association between antibiotic prescription and the independent variables were estimated using univariable logistic regression. The multivariable logistic regression model was fitted using backward elimination. All variables with $p<0.20$ in the univariable model were put together in the multivariable regression model. Using a cut-off of $p<0.20$ proved useful as some variables which were not significant at $p<0.05$ in the univariable model turned out to be significant in the multivariable model. From the analysis of collinearity, the highest variance inflation factors were 1.94 and 1.88 for ARTI and URTI, respectively. Robust standard errors were estimated using the "robust" option for all the models in Stata 14 (40). Statistical significance in the multivariable model was set at $p<0.05$. All analyses were done using Stata 14. Due to the large number of variables assessed, results are presented for only variables which were significant at $p<0.05$ in the multivariable model.

\section{Results}

Six hundred (600) patient folders with specific or non-specific RTI at the OPD of the Tema Polyclinic were sampled for the study. The largest proportion of the patients were children younger than 5 years $(n=252$, $42.1 \%)$. The proportion of females was $57.3 \%$. More than half $(52.3 \%)$ of patients were seen by medical doctors while the rest (47.7\%) were seen by physician assistants. A detailed description of background characteristics of patients is presented (Table 1 ). 
Table 1

Background characteristics of patients

\begin{tabular}{|lll|}
\hline Characteristics & Frequency, N=600 & $\%$ \\
\hline Age (in years) & & \\
\hline$<5$ & 252 & 42.1 \\
$\geq 5$ & 347 & 57.9 \\
\hline Sex & & \\
\hline Male & 256 & 42.7 \\
\hline Female & 344 & 57.3 \\
\hline NHIS & & \\
\hline Not registered & 157 & 29.5 \\
\hline Registered & 376 & 70.5 \\
\hline Occupation & & \\
\hline Pupil/student & 156 & 26.0 \\
\hline Formal employee & 16 & 2.7 \\
\hline Informal employee & 72 & 12.0 \\
\hline Not known & 356 & 59.3 \\
\hline
\end{tabular}

Of the 600 prescriptions assessed, 358 (59.7\%) had at least one (1) antibiotic. The total number of antibiotics prescribed was 379 . As shown in Table 2, majority of the prescribed antibiotics were penicillins $(n=270,71.2 \%)$. The other classes of antibiotics prescribed were cephalosporins $(n=57,15.0 \%)$, macrolides $(n=27,7.1 \%)$, quinolones $(n=10,2.6 \%)$, nitroimidazole $(n=8,2.1 \%)$, and other less frequently prescribed classes $(n=7,1.8 \%)$. The penicillins prescribed were amoxicillin, amoxicillin-clavulanic acid and flucloxacillin. Cefuroxime, ceftriaxone and cefixime were the cephalosporins prescribed, whereas azithromycin and erythromycin were the macrolides prescribed. 
Table 2

Distribution of prescribed antibiotic class and age group

\begin{tabular}{|llll|}
\hline Antibiotic class & \multicolumn{4}{l|}{ Age Group (years) } \\
\hline Penicillins & $<5$ & $\geq 5$ & Total \\
\hline Cephalosporins & $27(72.4)$ & $173(70.6)$ & $270(71.2)$ \\
\hline Macrolides & $4(3.0)$ & $30(12.2)$ & $57(15.0)$ \\
\hline Quinolones & $1(0.7)$ & $9(3.7)$ & $10(2.6)$ \\
\hline Nitroimidazole & $2(1.5)$ & $6(2.4)$ & $8(2.1)$ \\
\hline Others* & $3(2.2)$ & $4(1.6)$ & $7(1.8)$ \\
\hline Total & $134(100.0)$ & $245(100.0)$ & $379(100.0)$ \\
\hline *Tetracycline and cotrimoxazole & & \\
\hline
\end{tabular}

The distribution of the categorization using Kunin's modified criteria for antibiotic use is provided (Table 3). The majority $(68.2 \%, 409$ out of 600$)$ of the RTI cases could not be classified because the diagnoses were non-specific. Of the $31.8 \%(n=191)$ of folders which had specific diagnosis indicated, 121 had appropriate antibiotic prescription $(63.3 \%, 95 \% \mathrm{Cl}: 56.2,69.9)$. Regarding appropriateness in respect of choice of antibiotic, dose, and duration of therapy, $68.8 \%$ of inappropriate antibiotic prescription was because of wrong duration of therapy while $23.4 \%$ resulted from improper dose.

Table 3

Categorization of antibiotic prescription appropriateness using Kunin's modified criteria

\begin{tabular}{|lllll|}
\hline Category & Frequency & $\begin{array}{l}\text { \% of Total } \\
\text { Prescription }\end{array}$ & $\begin{array}{l}\text { \% of Prescriptions with specific } \\
\text { diagnoses }\end{array}$ & Remarks \\
\hline I & 107 & 17.8 & 56.0 & Appropriate \\
\hline II & 14 & 2.3 & 7.3 & Appropriate \\
\hline III & 1 & 0.2 & 0.5 & Inappropriate \\
\hline IV & 60 & 10.0 & 31.4 & Inappropriate \\
V & 9 & 1.5 & 4.7 & Inappropriate \\
\hline N/A & 409 & 68.2 & - & - \\
\hline N/A - cases which could not be evaluated for appropriateness because of non-specific diagnoses
\end{tabular}

The proportion of patients who were prescribed at least one (1) antibiotic was 59.7\% (95\% Cl: 55.7, 63.5) (Table 4). The frequency of antibiotic prescription did not differ significantly between males and females ( $p$ $=0.644)$. Based on age group the proportion of antibiotics prescribed was higher among those aged 5 years or older compared to those younger than 5 years. The frequency of prescribing antibiotics by Physician 
Assistants was higher compared to Medical Doctors (65.4\% vs $54.5 \%, p=0.006)$. Four (4) training / meeting sessions on drug-use were organized in 2018, while fifteen (15) copies of the 2017 Edition of the STG were purchased. However, none of the consulting rooms where prescribers attended to patients had copies available during the data collection period.

Table 4

Bivariate analysis of patient and prescriber factors by antibiotics prescription

Antibiotics

Not Prescribed $\mathbf{n}$

(\%)
Prescribed $n$

(\%)

Total, $\mathbf{N}=$ 600
Chi square $\mathrm{p}$-value

Patient factors

Age-group (in years)

$<5$

$\geq 5$

Sex

Male

Female

NHIS

No

Yes

57 (36.3)

$150(39.9)$

Occupation

Pupil/Student

Formal employee

Informal employee

Not known

Prescriber Factor

Prescriber's category

Medical Officer

$143(45.5)$

Physician Assistant

Total

99 (34.6)

$242(40.3)$
17.255

$<$

0.001 *

252 (100.0)

347 (100.0)

$232(66.9)$

0.214

0.644

256 (100.0)

$344(100.0)$

208 (60.5)

0.600

0.438

100 (63.7)

157 (100.0)

$226(60.1)$

376 (100.0)

9.038

0.029 *

156 (100.0)

$16(100.0)$

$8(50.0)$

72 (100.0)

52 (72.2)

356 (100.0)

$198(55.6) \quad 356(100.0)$

*statistically significant association relative to $p<0.05$ 
Other diagnoses made which were not related to RTI included malaria, allergies, dysentery, hypertension, enteric fever among others. The average number of drugs prescribed per prescription was 3.59. Drugs prescribed other than antibiotics included analgesics, haematinics, cough remedies, anti-hypertensives and anti-allergic drugs.

The variables which met the cut-off criterion of $p<0.20$ in the crude analyses were age group, laboratory investigations, breathlessness, occupation, professional category of prescriber, chest pain, headache, rhinorrhoea, sore throat, sneezing, catarrh, sputum production, otitis media, ARTI, common cold, pharyngitis, pneumonia, rhinitis, URTI, tonsillitis, sinusitis and nasal congestion. Of the 19 people diagnosed with pneumonia, all were not prescribed with antibiotics. Similarly, all 38 tonsillitis cases were not prescribed with antibiotics. These 2 diagnoses were not included in the regression analyses because each did not vary with regards to antibiotic prescription.

The variables which were significant in the adjusted analysis are presented in Table 5. Requesting laboratory investigations, presenting with breathlessness, headache and sputum production were associated with increased odds of antibiotic prescription in the adjusted model. Cases for which laboratory investigations were requested were $80.0 \%$ more likely to be prescribed with antibiotics after controlling for other significant variables.

The factors which were associated with reduced odds of antibiotic prescription were presenting with catarrh, a diagnosis of rhinitis, ARTI, URTI and common cold. After accounting for confounding factors, cases presenting with catarrh were $58.0 \%$ less likely to be prescribed with antibiotics (AOR $=0.42,95 \% \mathrm{Cl}$ : $0.27-0.66, p<0.001)$. Those diagnosed with common cold had $87.0 \%$ lower odds of antibiotic prescription, after adjusting for factors of interest (AOR $=0.13,95 \% \mathrm{Cl}: 0.05-0.31, \mathrm{p}<0.001)$. While in the crude model ARTI was associated with 1.9 times increased odds of antibiotic prescription (AOR $=1.92,95 \%$ Cl: $1.37-$ $2.68, p<0.001$ ), in the adjusted model it was associated with $59 \%$ reduced odds of antibiotics prescription $(\mathrm{AOR}=0.41,95 \% \mathrm{Cl}: 0.23-0.74, \mathrm{p}=0.003)$. 
Table 5

Crude and Adjusted Odds Ratios of Factors Associated with Antibiotic Prescription

\begin{tabular}{|c|c|c|c|c|}
\hline Variables & $\begin{array}{l}\text { Crude OR } \\
(95 \% \mathrm{Cl})\end{array}$ & P-value & $\begin{array}{l}\text { Adjusted OR } \\
(95 \% \mathrm{Cl})\end{array}$ & P-value \\
\hline \multicolumn{5}{|c|}{ Laboratory investigation (Ref: No) } \\
\hline Yes & $1.98(1.42,2.76)$ & $<0.001$ & $1.80(1.22,2.64)$ & 0.003 \\
\hline \multicolumn{5}{|c|}{ Breathlessness (Ref: No) } \\
\hline Yes & $6.93(0.88,54.45)$ & 0.066 & $9.01(1.11,73.09)$ & 0.04 \\
\hline \multicolumn{5}{|c|}{ Catarrh (Ref: No) } \\
\hline Yes & $0.50(0.33,0.77)$ & $<0.001$ & $0.42(0.27,0.66)$ & $<0.001$ \\
\hline \multicolumn{5}{|c|}{ Headache (Ref: No) } \\
\hline Yes & $2.09(1.47,2.99)$ & $<0.001$ & $1.77(1.16,2.71)$ & 0.009 \\
\hline \multicolumn{5}{|c|}{ Sputum (Ref: No) } \\
\hline Yes & $3.36(2.04,5.53)$ & $<0.001$ & $3.49(1.96,6.22)$ & $<0.001$ \\
\hline \multicolumn{5}{|c|}{ Rhinitis (Ref: No) } \\
\hline Yes & $0.40(0.14,1.10)$ & 0.076 & $0.20(0.06,0.73)$ & 0.015 \\
\hline \multicolumn{5}{|c|}{ ARTI (Ref: No) } \\
\hline Yes & $1.92(1.37,2.68)$ & $<0.001$ & $0.41(0.23,0.74)$ & 0.003 \\
\hline \multicolumn{5}{|c|}{ URTI (Ref: No) } \\
\hline Yes & $0.25(0.18,0.37)$ & $<0.001$ & $0.11(0.06,0.20)$ & $<0.001$ \\
\hline \multicolumn{5}{|c|}{ Common cold (Ref: No) } \\
\hline Yes & $0.23(0.12,0.43)$ & $<0.001$ & $0.13(0.05,0.31)$ & $<0.001$ \\
\hline
\end{tabular}

\section{Discussion}

This study presents the outcome of audit of prescriptions of antibiotics in the management of RTIs at Tema Polyclinic (a primary healthcare facility) in Ghana. It also sought to identify the factors that are associated with such prescriptions.

\section{Patient Demographics}

The highest proportion of patients were less than 5 years old (42.1\%). This is consistent with the general trend identified in several studies that have identified higher incidence of RT Is in children, especially those 
below the age of 5 years $(1,6,7)$. This is often attributed to their immature respiratory tissues and organs to adequately deal with such infections. It also point to the need to pay particular attention to this age group in the implementation of interventions aimed at controlling and managing RTIs.

Female patients with RTIs were more compared to males. This may be attributed to the general view that females have better health-seeking behaviour compared to males (41). It may also be due to the fact that the incidence of RTIs are higher in females than in males (42).

Most of the patients were NHIS card holders (70.5\%). This can be attributed to the fact that Tema Polyclinic is the major public health facility in the municipality that offers full service (i.e. consultation and medicines) to NHIS clients.

\section{Prescription of Antibiotics}

More than half $(59.7 \%)$ of the RTI patients in the present study received at least one antibiotic. This is comparable to the $59.0 \%$ antibiotic prescription in a study in NANTES University hospital (43) and $63 \%$ from the National Ambulatory Medical Care Survey (44) . Conversely, our estimate is lower than $67.5 \%$ and $82.5 \%$, obtained in the study at Ridge Hospital and Adabraka Polyclinic, Accra, Ghana, respectively (18). It must be noted that Apenteng and colleagues' study was conducted among children under less than 5 years. Compared to antibiotic prescription among the children under five in our study, our estimate of $50.0 \%$ was lower. Since most RTIs are of viral origin $(4,11)$, the high proportion of antibiotic prescription use in the management of RTI needs to be addressed.

The three topmost classes of antibiotics from which prescriptions were made for RTI cases in the study were penicillins, cephalosporins and macrolides. Other studies have also identified same for the management of RTIs $(45,46)$. These are also the $1^{\text {st }}$ and $2^{\text {nd }}$ line options recommended by the STG when an antibiotic is indicated for a specific RTI management. The pattern is also similar to that in the study by

Sumaila and Tabong (2018) where the percentage prescription of penicillins, cephalosporins and macrolides for URTI management were $58 \%, 19 \%$ and $10 \%$ respectively. In addition, similar specific antibiotics within these classes were identified in both studies with amoxicillin, amoxicillin + clavulanic acid and cefuroxime as the most prescribed, except that the latter was in URTIs management. The STG recommends amoxicillin as the first line antibiotic in most cases of specified RTIs where it is indicated with amoxicillin + clavulanic acid and cefuroxime as the second line options. The choice of specific agents for RTI management is therefore consistent with the STG requirements.

\section{Appropriateness of Antibiotic Prescription}

The proportion of patients appropriately prescribed antibiotics, from the study, was (63.3\%, 95\% Cl: 56.2 , 69.9). This is comparable to the $70.4 \%$ found at a secondary referral hospital in Ghana but at variance with the $34.6 \%$ found at a primary referral hospital also in Ghana (18). Unlike the present study, the other studies were conducted in children under 5 years. Most of the inappropriateness resulted from inappropriate duration of antibiotic use. A longer duration than is recommended may mean exposing bacteria excessively to antibiotics thereby facilitating the emergence of resistant strains. On the other hand, a shorter duration

Page $12 / 19$ 
may imply a higher chance of treatment failure. This may necessitate retreatment leading to a cumulatively longer duration of bacterial exposure (47). Further studies to describe inappropriate duration of antibiotic use and to ascertain the associated factors are required.

\section{Associated factors with antibiotic prescription}

The treatment recommendation for RTIs by the STG like all other disease conditions, are based on specific diagnosis. This prevents blind treatment and ensures rational use of medicines. The majority $(68.2 \%)$ of the RTI cases from this study could not be classified because they were not specific. The $31.8 \%$ with specific RTI diagnoses observed in this study is far below $67.5 \%$ and $65.0 \%$ obtained in the study at Ridge hospital and Adabraka polyclinic, respectively (18). This raises issues with clinical diagnosing of RT Is at Tema polyclinic and may point to the fact that prescribers are more comfortable making a broad diagnosis of RTI or URTI instead of distinguishing the types. This also gives room for empirical use of antibiotics with its public health implications. With the NHIS using the STG recommendations in vetting claims, the facility stands to lose revenue and that has implications for quality and sustainability of service provision. It is particularly worrying since most of the patients access care through their NHIS membership.

In this study, all patients diagnosed with pneumonia or tonsillitis were not prescribed with antibiotics suggesting that prescribers may be thinking that these infections were not caused by bacteria. This position is corroborated by the finding that all the significant diagnoses were associated with reduced odds of antibiotic prescription. Contrary to the finding that in different geographic locations bronchitis is consistently associated with higher odds of antibiotic prescription, our study did not find enough evidence to support this (31). As have been reported, uncomplicated bronchitis does not require treatment with antibiotics (48). Our findings suggest that in line with this, prescribers do not suspect any underlying bacterial infection when treating these conditions.

A study in the USA found sputum and breathlessness to be associated with antibiotic prescription (32). These observations are consistent with findings from our study. Coloured sputum production have also been observed to be associated with antibiotic prescription in a multi-country study too (33). The prescribers may be perceiving these symptoms as being indicative of bacterial infection. Since evidence from the literature does not support this antibiotic prescribing behaviour, it must be addressed to help control high and irrational prescribing of antibiotics.

Our findings that laboratory investigations is linked to high antibiotic prescription is comparable to a study in Switzerland (30). In the latter study, elevated white blood cell count was associated with high antibiotic prescription. In a related study in Uganda, the investigators found that patients who underwent laboratory investigations and tested negative for malaria were more likely to be prescribed antibiotics (29).

Furthermore, among those who did not undergo laboratory testing, diagnostic uncertainty is likely to predispose them to higher antibiotic prescription. In a population where the white cell count and negative malaria testing results may be relatively high, as it may be among those who underwent diagnostic testing in our study, higher antibiotic prescription may be expected. These findings may explain the observation that laboratory testing was significantly associated with antibiotic prescription in this study.

Page 13/19 
One strength of our study is that it narrows down to RTIs which have been shown to be the most common infection treated with antibiotics by several studies. Regarding limitations, the factors assessed were limited by the records review design. Also, we could not verify if recorded diagnoses by prescribers were wholly consistent with the international classification of diseases.

\section{Conclusion}

Although many patients with specific diagnoses were prescribed antibiotics appropriately, some RTI cases received prescriptions of antibiotics with inadequate dosage regimen. Majority of RTI cases were prescribed antibiotics. Commonly prescribed antibiotics were amoxicillin, amoxicillin plus clavulanic acid (penicillins), cefuroxime (cephalosporin) and azithromycin (macrolide). Factors influencing high antibiotic prescription were presenting with sputum production, breathlessness, headache and having undergone laboratory investigations.

Antibiotic stewardship efforts should focus on imparting knowledge on specific diagnoses and corresponding treatment with emphasis on dosage regimen while deemphasizing symptomatic treatment based on sputum production.

\section{List Of Abbreviations}

ARTI Acute Respiratory Tract Infection

DTC Drugs and Therapeutics Committee

HIV Human Immunodeficiency Virus

NHIS National Health Insurance Scheme

OPD Outpatient Department

RTI Respiratory Tract Infection

STG Standard Treatment Guidelines

TB Tuberculosis

URTI Upper Respiratory Tract Infection

\section{Declarations}

\section{Ethics Approval and Consent to Participate}

All the included folders were de-identified to preserve the privacy of patients and prescribers. Ethical clearance was obtained from the Ethics Review Committee of the Ghana Health Service. In addition, the Medical superintendent of the Polyclinic granted permission for the study to be conducted. 


\section{Consent for publication}

Consent for publication was obtained from the Management of Tema Polyclinic.

\section{Availability of Data and Material}

The dataset is not publicly available. However, it can be accessed after a reasonable request has been sent to the corresponding author.

\section{Competing Interests}

The authors declare that they have no competing interests.

\section{Funding}

Funding for the original study was provided by Joel Jeffrey Idun-Acquah.

\section{Authors' Contributions}

JJIA conceptualised and designed this research which formed a component of his training requirements for the award of Fellowship at the West African Postgraduate College of Pharmacists. HAB supervised the entire research project. MM and EK contributed to data management, analyses and interpretation. JJIA and MM produced the first draft of the manuscript. All authors reviewed and approved the final manuscript for submission.

\section{Acknowledgements}

We would like to acknowledge Dr. Sally D. Quartey and the Drugs and Therapeutics Committee of Tema Polyclinic for their technical advice and support throughout the data collection period. Special thanks to Miss Irene A. Boateng and Mr. Edwin Martey for assisting with data collection. We are grateful to Dr. Adolf Awua, and Mr. Daniel Afriyie for reviewing and editing the manuscript.

\section{References}

1. Ahiabu MA, Tersbøl BP, Biritwum R, Bygbjerg IC, Magnussen P. A retrospective audit of antibiotic prescriptions in primary health-care facilities in Eastern Region, Ghana. Health Policy Plan [Internet]. 2016;31(2):250-8. Available from: http://www.scopus.com/inward/record.url?eid=2-s2.084964670049\&partnerlD=tZOtx3y1

2. Akkerman A, Kuyvenhoven $M$, Wouden $J$ Van Der, Verheij T. Prescribing antibiotics for respiratory tract infections by GPs: management and prescriber characteristics. Br J Gen Pract [Internet]. 2005;55(February):114-8. Available from: https://bjgp.org/content/bjgp/55/511/114.full.pdf

3. Bjerrum L, Munck A, Gahrn-Hansen B, Hansen MP, Jarbol DE, Cordoba G, et al. Health Alliance for prudent antibiotic prescribing in patients with respiratory tract infections (HAPPY AUDIT) -impact of a non-randomised multifaceted intervention programme. BMC Fam Pract [Internet]. 2011;12:52. Available 
from: http://www.embase.com/search/results?

subaction=viewrecord\&from=export\&id=L362998192\%0Ahttp://dx.doi.org/10.1186/1471-2296-12-

52\%0Ahttp://sfx.library.uu.nl/utrecht?sid=EMBASE\&issn=14712296\&id=doi:10.1186\%2F1471-2296-1252\&atitle=Health+Alliance+for+prudent

4. Fahey T, Stocks $\mathrm{N}$, Thomas $\mathrm{T}$. Systematic review of the treatment of upper respiratory tract infection. Arch Dis Child. 1998;79(3):225-30.

5. Picazo JJ, Perez-Cecilia E, Herreras A. [Respiratory infections outside the hospital. DIRA study]. Enferm Infecc Microbiol Clin. 2003;21(8):410-6.

6. Biezen R, Brijnath B, Grando D, Mazza D. Management of respiratory tract infections in young children A qualitative study of primary care providers' perspectives. npj Prim Care Respir Med [Internet]. 2017;27(1):1-6. Available from: http://dx.doi.org/10.1038/s41533-017-0018-x

7. Tabatabaei SA, Fahimzad SA, Shamshiri AR, Shiva F, Salehpor S, Sayyahfar S, et al. Assessment of a new algorithm in the management of acute respiratory tract infections in children. J Res Med Sci. 2012;17(2):182-5.

8. WHO. Global Health Estimates 2016: Deaths by Cause, Age, Sex, by Country and by Region, 2000-2016. [Internet]. Geneva; 2018. Available from: http://www.who.int/healthinfo/global_burden_disease/estimates/en/

9. WHO. Global Health Estimates 2016: Disease burden by Cause, Age, Sex, by Country and by Region, 2000-2016. [Internet]. Geneva; 2018. Available from:

http://www.who.int/healthinfo/global_burden_disease/en/\%0A

10. GHS. The Health Sector in Ghana, Facts and Figures [Internet]. 2018 [cited 2019 Mar 27]. Available from: http://www.ghanahealthservice.org/downloads/Facts+Figures_2018.pdf

11. McDonagh M., Peterson K, Wintrhtop K, Cantor A, Holzhammer B, Buckley DI. Interventions to Improve Appropriate Antibiotic Use for Acute Respiratory Tract Infections. Comp Eff Rev. 2014;2014(163).

12. NICE. Respiratory tract infections - antibiotic prescribing. Prescribing of antibiotics for self-limiting respiratory tract infections in adults and children in primary care. NICE Clin Guidel 69. 2008;69(July):1240.

13. Dowell J, Pitkethly M, Bain J, Martin S. A randomised controlled trial of delayed antibiotic prescribing as a strategy for managing uncomplicated respiratory tract infection in primary care. 2001; (March):200-5.

14. Drekonja DM, Filice GA, Greer N, Olson A, MacDonald R, Rutks I, et al. Antimicrobial stewardship in outpatient settings: A systematic review. Infect Control Hosp Epidemiol. 2015;36(2):142-52.

15. Gerber JS, Prasad PA, Fiks AG, Localio AR, Grundmeier RW, Bell LM, et al. Effect of an outpatient antimicrobial stewardship intervention on broad-spectrum antibiotic prescribing by primary care pediatricians a randomized trial. JAMA - J Am Med Assoc. 2013;309(22):2345-52.

16. Köchling A, Löffler C, Reinsch S, Hornung A, Böhmer F, Altiner A, et al. Reduction of antibiotic prescriptions for acute respiratory tract infections in primary care: A systematic review. Implement Sci. 2018;13(1).

17. Holloway K, Green T. Drug and Therapeutics Committees: A Practical Guide. Vol. WHO/EDM/PA. 2004. 
18. Apenteng JA, Addy BS, Onwukwe EO, Brookman-Amissah G. Antibiotics prescribing patterns and incidence of respiratory tract infection in children under five years: A study in two hospitals in Accra , Ghana. Int J Med Med Sci. 2018;10(4):47-58.

19. Gulliford MC, Dregan A, Moore M V., Ashworth M, Van Staa T, McCann G, et al. Continued high rates of antibiotic prescribing to adults with respiratory tract infection: Survey of $568 \mathrm{UK}$ general practices. BMJ Open. 2014;4(10):1-5.

20. Shively NR, Buehrle DJ, Clancy CJ, Decker BK. Prevalence of inappropriate antibiotic prescribing in primary care clinics within a veterans affairs health care system. Antimicrob Agents Chemother. 2018;62(8):1-7.

21. Lee GC, Reveles KR, Attridge RT, Lawson KA, Mansi IA, Lewis JS, et al. Outpatient antibiotic prescribing in the United States: 2000 to 2010. BMC Med. 2014;12(1).

22. Xu KT, Roberts D, Sulapas I, Martinez O, Berk J, Baldwin J. Over-prescribing of antibiotics and imaging in the management of uncomplicated URIs in emergency departments. BMC Emerg Med. 2013;13(1):16.

23. Boonstra $\mathrm{E}$, Lindbæk M, Ngome $\mathrm{E}$. Adherence to management guidelines in acute respiratory infections and diarrhoea in children under 5 years old in primary health care in Botswana. Int J Qual Heal Care [Internet]. 2005;17(3):221-7. Available from: http://www.ncbi.nlm.nih.gov/pubmed/15723818

24. Gwimile JJ, Shekalaghe SA, Kapanda GN, Kisanga ER. Antibiotic prescribing practice in management of cough and/or diarrhoea in moshi municipality, northern tanzania: Cross-sectional descriptive study. Pan Afr Med J. 2012;12(1):1-8.

25. Kibuule D, Kagoya HR, Godman B. Antibiotic use in acute respiratory infections in under-fives in Uganda: findings and implications. Expert Rev Anti Infect Ther. 2016;14(9):863-72.

26. Cars O, Hedin A, Heddini A. The global need for effective antibiotics - Moving towards concerted action. Drug Resist Updat [Internet]. 2011;14(2):68-9. Available from: http://dx.doi.org/10.1016/j.drup.2011.02.006

27. WHO. Antibiotic Resistance: Key Facts. 2018;(February). Available from: https://www.who.int/newsroom/fact-sheets/detail/antibiotic-resistance

28. Deshmukh A, Ghadlinge M, Tamboli S, Deshmukh J, Chhabra R. Study of rationality and utilization pattern of antimicrobials in ear, nose, throat outpatient department of Tertiary Care Hospital, Nanded. Int J Basic Clin Pharmacol. 2015;4(4):734-8.

29. Batwala V, Magnussen P, Nuwaha F. Antibiotic use among patients with febrile illness in a low malaria endemicity setting in Uganda. Malar J [Internet]. 2011;10(1):377. Available from: http://www.malariajournal.com/content/10/1/377

30. Gotta V, Baumann P, Ritz N, Fuchs A, Baer G, Bonhoeffer JM, et al. Drivers of antibiotic prescribing in children and adolescents with febrile lower respiratory tract infections. PLoS One. 2017;12(9):1-15.

31. McKay R, Mah A, Law MR, McGrail K, Patrick DM. Systematic Review of Factors Associated with Antibiotic Prescribing for Respiratory Tract Infections. Antimicrob Agents Chemother. 2016;60(7):410618. 
32. Aspinall SL, Good CB, Metlay JP, Mor MK, Fine MJ. Antibiotic prescribing for presumed nonbacterial acute respiratory tract infections. Am J Emerg Med [Internet]. 2009 Jun 1 [cited 2020 Jun 26];27(5):544-51. Available from: https://linkinghub.elsevier.com/retrieve/pii/S0735675708003252

33. Butler CC, Kelly MJ, Hood K, Schaberg T, Melbye H, Serra-Prat M, et al. Antibiotic prescribing for discoloured sputum in acute cough/lower respiratory tract infection. Eur Respir J. 2011;38(1):119-25.

34. Dosh SA, Hickner JM, Mainous AG, Ebell MH. Predictors of Antibiotic Prescribing for Nonspecific Upper Respiratory Infections, Acute Bronchitis, and Acute Sinusitis. J Fam Pract [Internet]. 2000;407. Available from: https://go.galegroup.com/ps/anonymous? $\mathrm{id}=\mathrm{GALE} \% 7 C A 62723370 \&$ sid=googleScholar\&v=2.1\&it=r\&linkaccess=abs\&issn=00943509\&p=AONE\& $\ldots$

35. Murray S, Del Mar C, O’Rourke P. Predictors of an antibiotic prescription by GPs for respiratory tract infections: a pilot. Fam Pract. 2000;17(5):386-8.

36. $\mathrm{MOH}$. Policy on Antimicrobial Use and Resistance [Internet]. 1st ed. Ministry of Health, Ghana; 2017.48 p. Available from: http://www.moh.gov.gh/wp-content/uploads/2018/04/AMR-POLICY-A5_09.03.2018Signed.pdf

37. NHIA. National Health Insurance Authority's Report on Vetted Claims for Tema Polyclinic: January, 2016 to June, 2018. 2018.

38. GHS/GNDP. Standard Treatment Guidelines, 2017 [Internet]. 7th ed. Vol. 7th editio, Standard Treatment Guidelines. MINISTRY OF HEALTH (GNDP), GHANA; 2017. 167-174 p. Available from: www.ghndp.org/app/stg/

39. WHO Collaborating Centre for Drug Statistics Methodology. Guidelines for ATC classification and DDD assignment [Internet]. 16th ed. 2013. 1-284 p. Available from:

https://www.whocc.no/filearchive/publications/1_2013guidelines.pdf

40. StataCorp. Statistical Software. 2015.

41. Galdas PM, Cheater F, Marshall P. Men and health help-seeking behaviour: Literature review. J Adv Nurs [Internet]. 2005;49(6):616-23. Available from: https://onlinelibrary.wiley.com/doi/abs/10.1111/j.13652648.2004.03331.x

42. Hak E, Rovers MM, Kuyvenhoven MM, Schellevis FG, Verheij TJM. Incidence of GP-diagnosed respiratory tract infections according to age, gender and high-risk co-morbidity: The Second Dutch National Survey of General Practice. Fam Pract. 2006;23(3):291-4.

43. Marc C, Vrignaud B, Levieux K, Robine A, Guen CG Le, Launay E. Inappropriate prescription of antibiotics in pediatric practice: Analysis of the prescriptions in primary care. J Child Heal Care. 2016;20(4):530-6.

44. Rebnord IK, Sandvik H, Mjelle AB, Hunskaar S. Factors predicting antibiotic prescription and referral to hospital for children with respiratory symptoms: Secondary analysis of a randomised controlled study at out-of-hours services in primary care. BMJ Open. 2017;7(1):1-8.

45. Steinman MA. Predictors of Broad-Spectrum Antibiotic Prescribing for Acute Respiratory Tract Infections in Adult Primary Care. JAMA [Internet]. 2003 Feb 12;289(6):719. Available from: http://jama.jamanetwork.com/article.aspx?doi=10.1001/jama.289.6.719 
46. Sumaila AN, Tabong PTN. Rational prescribing of antibiotics in children under 5 years with upper respiratory tract infections in Kintampo Municipal Hospital in Brong Ahafo Region of Ghana. BMC Res Notes [Internet]. 2018;11(1):1-5. Available from: https://doi.org/10.1186/s13104-018-3542-z

47. Pugh R, Grant C, Cooke RPD, Dempsey G. Short-course versus prolonged-course antibiotic therapy for hospital-acquired pneumonia in critically ill adults ( Review) SUMMARY OF FINDINGS FOR THE MAIN COMPARISON. Cochrane Database Syst Rev. 2015;(8):1-43.

48. Smith SM, Smucny J, Fahey T. Antibiotics for acute bronchitis [Internet]. Vol. 312, JAMA - Journal of the American Medical Association. 2014. p. 2678-9. Available from:

https://doi.org/10.1001/jama.2014.12839

\section{Supplementary Files}

This is a list of supplementary files associated with this preprint. Click to download.

- SubmissionofmanuscriptLetterARICjournal.docx 